\title{
Impact of COVID-19 on Port Production and Operation Based on System Dynamics: A Case Study of Shanghai Port in China
}

\author{
Zili Tai $\mathbb{D}^{1},{ }^{1}$ Ji Guo $\left(D,{ }^{1,2}\right.$ Yeli Guan $\left(\mathbb{D},{ }^{3}\right.$ and Qingquan Shi ${ }^{4}{ }^{4}$ \\ ${ }^{1}$ School of Economics and Management, Shanghai Maritime University, Shanghai 201306, China \\ ${ }^{2}$ Collaborative Innovation Center on Climate and Meteorological Disasters, Nanjing 210044, China \\ ${ }^{3}$ Meteorological Bureau of Linyi City, Linyi 276007, China \\ ${ }^{4}$ College of Art and Science, University of California, Davis, CA, USA
}

Correspondence should be addressed to Ji Guo; 185391@shmtu.edu.cn

Received 23 April 2021; Revised 30 May 2021; Accepted 11 August 2021; Published 20 August 2021

Academic Editor: Antonio Comi

Copyright $\odot 2021$ Zili Tai et al. This is an open access article distributed under the Creative Commons Attribution License, which permits unrestricted use, distribution, and reproduction in any medium, provided the original work is properly cited.

\begin{abstract}
Since the end of 2019, the outbreak of COVID-19 has severely affected port production and operation. There is little research on the systematic impact assessment. This study took Shanghai Port as an example and evaluated the impact under different scenarios through establishing a System Dynamics model. It is found that the epidemic mainly has a greater impact on passenger transport, but less on cargo transport. The ports with the function of transportation in highway, railway, and waterway were the key nodes in the international logistics network. More attention should be paid to the impact assessment of COVID-19 on ports' production and operation. It is necessary to strengthen the port's collection and distribution capabilities, improve port production efficiency, and further strengthen port modernization. This research method proposed in this paper can provide a reference for the impact assessment of similar events, and the empirical results can provide a reference for handling the epidemic shock for the port and shipping departments.
\end{abstract}

\section{Introduction and Background}

The new coronavirus pneumonia (COVID-19) that outbroke in Wuhan in December 2019 has severely affected people's lives. With effective prevention and control of COVID-19, China's domestic production has begun to return to normal gradually, as well as the port industry. However, the epidemic situation abroad remains severe, especially in India. Of the approximately 1.7 million sailors in the world, more than 0.2 million are from India. Many countries have banned flights from India, and Indian workers cannot travel to other ports. The global shipping industry and port industry have also been affected. As the virus continues to mutate abroad, the sustained impact of the epidemic on our country in the future is still uncertain.

After COVID-19 outbroke, the Chinese government adopted a series of measures to prevent the spread of COVID-19. Those who were uninfected chose home quarantine because of the holiday extension policy, while those who were infected were willing to get quarantine treatment at assembly sites. Meanwhile, those antiepidemic measures have severely affected the normal operation of several industries in industry, tourism, transportation, postal storage, and domestic and foreign trade. For example, COVID-19 has caused a shortage of port equipment, reduction of port staff, closure of some transportation routes, and backlog of goods in terminals, warehousing, and distribution centers. A large number of containers have become stranded, resulting in high detention fees. Those transfer stains have become storage stations. However, how to systematically assess the magnitude of the COVID-19's impact on port's production and operation is still rare to be seen in current research. This paper took the Shanghai Port as an example and studied the impact of the epidemic on the port based on the System Dynamics model. The empirical ideas and methods proposed in this paper can provide a reference for combating the COVID-19 shock and adopting disaster prevention and relief measures for Shanghai Port. 


\section{Literature Review}

Scholars have used the System Dynamics model to study the operation process of the port. System dynamics can deeply simulate the impact path and degree of emergencies based on the mutual causality of the internal components of the system, so it is widely used in the impact assessment of emergencies. By considering the impact of various main factors on port throughput, Xu et al. [1] took Ningbo Port as an example and tried to minimize the port throughput forecasting error by reducing the uncertainty of economic and social development level. Luan et al. [2] proposed the system dynamic flowchart and related equations by using VENSIM software and studied the feedback relationship between the variables and the structure in port-city system. Jiang et al. [3] took Tianjin as an example, established three subsystems in economy, transportation network, and transportation investment, and analyzed the impact of different investment proportions in collection and distribution system on the port's collection and distribution capacity. Yu et al. [4] divided the land transportation system into economic, transportation network, and transportation investment subsystems and built a System Dynamics model to simulate the interactions between the transportation system and the economic system of port cities.

Scholars also used System Dynamics models to study the development of port clusters. Wang and Cui [5] constructed a System Dynamics model to study the coordinated development of the logistics system of Shanghai Port and Ningbo Port. Xi [6] applied the System Dynamics method to analyze the causal relationship of the development of Suzhou combination port and the feedback relationships among transportation demand, capacity supply, and economic development. Yu and Liu [7] constructed a System Dynamics model of port clusters and studied the impact of competition and learning effects between ports on the overall efficiency of port clusters. Pan et al. [8] took Lianyungang as an example to establish a System Dynamics model of the port-city coupling based on the system characteristics of the port city, the boundary of the system model, and the causality of system elements.

The sustainable development of port economy has always been a hot topic. Scholars have conducted research on the sustainable development of ports from different fields. Liu et al. [9] took Dalian Port as an example to study the dynamic impact of the port on the social economy by using System Dynamics model, input-output method, multiplier method, and econometric methods. Fu and Lv [10] established a System Dynamics model of the port-regional economic system and studied the relationship between ports and regional economic development. Hou [11] established a System Dynamics model and analyzed the dynamic mechanism of sustainable development of port economy. Guo et al. [12] took Shenzhen as an example to construct a System Dynamics model for the green and low-carbon development of port cities and studied its validity of the system model. Hou and Geerlings [13] studied the sustainable development of transportation system of Shanghai Port and its hinterland and improved the sustainable transportation performance of the port hinterland through a System Dynamics model. Zhang et al. [14] constructed a System Dynamics model for port ecological carrying capacity from the aspects of social economy, resources, and environment, evaluated the port ecological carrying capacity, and predicted its evolution trend. Wen et al. [15] constructed a System Dynamics model for the emission reduction of regional ships and predicted the trend of shipping economic benefits and regional vessel exhaust emissions under different scenarios. Geng et al. [16] took Qingdao Port as an example, established the System Dynamics model, and studied the emissions of ships in the port. Qiao et al. [17] took Lianyungang as an example and established a port-city coupling System Dynamics model, which takes into account the interactions among various elements in the economic-energy-environment complex system. Li et al. [18] constructed a System Dynamics model to measure the role of ports in cities and proposed countermeasures and suggestions for promoting the green and coordinated development of port cities. Mamatok et al. [19] applied System Dynamics models to analyze the carbon emissions of port container transportation. Zheng et al. [20] constructed a System Dynamics model and studied the influence of container port core operation capacity and environmental pollution control capacity on the green growth of the port economy to get the best green investment decision-making plan. Zhou et al. [21] established the dynamics model of port energy saving and emission reduction system and analyzed the implementation effects under different policy conditions. Feng et al. [22] applied System Dynamics to simulate the ecological carrying capacity of Qinzhou Port and compared the ecological carrying capacity of Qinzhou Port in multiple scenarios. Zuo [23] established a port-city coupling System Dynamics model and analyzed the problems of environmental pollution control and land resource allocation in the coupling process. Sun et al. [24] applied the System Dynamics model to improve the safety level of port operation by analyzing the influencing factors of port operation and exploring the interaction between safety investment and system risk level. Li et al. [25] applied the System Dynamics model to study the impact of port trade on the regional economy and made relevant analysis through practical applications. Huang et al. [26] established a System Dynamics model of the greenhouse gas emissions and studied the issue of emission reduction in container ports. Xiu and Zhao [27] researched the sustainable development of the port economy based on network intelligent sensor technology and system dynamics.

Since the outbreak of COVID-19, some scholars have studied the impact of COVID-19 on the port economy and environment. Dawn et al. [28] built a framework for port logistics capability and studied the uncertainty of the container logistics supply chain. Su et al. [29] made an analysis of the impact of COVID-19 on the import and export trade of Shanghai Port by comparing its export data from January to May in 2019 and 2020. By comparing the difference in the number of ships inspected from 2017 to 2020, Akyurek and Bolat [30] studied the number of ship's variations in the port during COVID-19. Notteboom et al. [31] compared the 
different impacts of COVID-19 and the 2008 financial crisis on the supply and demand of container ports and the shipping industry. Hajar et al. [32] evaluated the impact of COVID-19 on container transportation in the Tanger Med port in Morocco. Koyuncu et al. [33] established the time series model by using the Institute of Shipping Economics and Logistics (ISL) and the Leibniz International Airport Container Throughput Index (RWI), revealing the impact of COVID-19 on the forecast results of the short-term throughput index. Duran-Grados et al. [34] analyzed the changes in the emissions of passenger ships from the Strait of Gibraltar during the COVID-19 pandemic. In terms of the impact of COVID-19 on the port environment, Curovic et al. [35] compared the noise emissions before and after the occurrence of COVID-19 based on the noise data from three monitoring stations. Zabbey et al. [36] analyzed the air quality changes of Harcourt Port before and after its closure due to the COVID-19 outbreak. Chen et al. [37] conducted a field campaign in Ningbo to measure the impact of the COVID-19 on air pollutants including $\mathrm{NO}_{2}, \mathrm{O}_{3}$, and $\mathrm{CO}$ from 21 January to 23 March 2020.

Researchers would like to adopt the static mathematical models to study the impact of COVID-19 on ports in most of the current literature although it is difficult to describe the dynamic changes of complex nonlinear systems. It is rare to see studies on analyzing the causal relationship between the internal structure of the port and various elements. Taking into account the complexity of the port and its supply system, we constructed a System Dynamics model to distinguish different scenarios and made a simulation analysis of the research path and the impact of COVID-19 on the port system. The results can provide references for various departments to take targeted countermeasures.

\section{Development of Port System Dynamics Model}

3.1. Research Route. There following steps are in the study as shown in Figure 1:

(1) Determine the main factors in the port's production and operation system. Consider three major factors including environment, transportation, and economy. Establish a port production and operation model. Meanwhile, consider the impact of the epidemic on the port production and operation model.

(2) Based on the port production and operation model, draw a causal feedback diagram and a flowchart of the port's production and operation.

(3) Take Shanghai Port as an example to conduct an empirical analysis of the impact of the epidemic on the port's production and operation by simulating three different scenarios (when the epidemic is aggravated, weakened, and unchanged).

The idea of this research is shown in Figure 1.

3.2. Causal Feedback Loop. Feedback is a basic idea of system dynamics, which transmits the consequences of historical behavior to the system itself to influence the behavior of the next stage. The causal feedback loop is an end-to-end causal chain formed by the interaction of cause and effect and plays an important role in the System Dynamics model. There are the following causal feedback loops affecting the port throughput:

(1) Loop 1. GDP $\longrightarrow$ increment of retail sales in consumer goods $\longrightarrow$ increment of domestic trade cargo throughput $\longrightarrow$ increment of port throughput $\longrightarrow$ port throughput $\longrightarrow$ growth rate of GDP $\longrightarrow$ GDP

With the increase in GDP, the total retail sales of social consumer goods will also increase, which leads to an increase in port throughput while domestic trade cargo throughput increases. Finally, it promoted an increase in GDP and formed a positive feedback loop.

(2) Loop 2. GDP $\longrightarrow$ increment of industrial output $\longrightarrow$ increment of domestic trade cargo throughput $\longrightarrow$ increment of port throughput $\longrightarrow$ port throughput $\longrightarrow$ growth rate of GDP $\longrightarrow$ GDP

With the increase of GDP, the total industrial output will increase, which leads to an increase in port throughput while domestic trade cargo throughput increases. Finally, it promoted an increase in GDP and formed a positive feedback loop.

(3) Loop 3. GDP $\longrightarrow$ increment of industry in transportation, storage, and postal $\longrightarrow$ increment of domestic trade cargo throughput $\longrightarrow$ increment of port throughput $\longrightarrow$ port throughput $\longrightarrow$ growth rate of $\mathrm{GDP} \longrightarrow \mathrm{GDP}$

With the increase of GDP, the total output of industry in transportation, storage, and postal will increase, which leads to the increase in port throughput while domestic trade cargo throughput increases. Finally, it promoted an increase in GDP and formed a positive feedback loop.

(4) Loop 4. GDP $\longrightarrow$ fixed asset investment $\longrightarrow$ increase in port throughput $\longrightarrow$ increment of port throughput $\longrightarrow$ port throughput GDP growth rate $\longrightarrow$ GDP

With the increase of GDP, investment in fixed assets will increase, which leads to an increase in port throughput. Finally, it promoted an increase in GDP and formed a positive feedback loop.

(5) Loop 5: GDP $\longrightarrow$ increment of import and export trade $\longrightarrow$ increment of foreign trade cargo throughput $\longrightarrow$ port throughput $\longrightarrow$ GDP growth rate $\longrightarrow$ GDP With the increase of GDP, the total volume of import and export trade will also increase, which leads to an increase in port throughput while foreign trade cargo throughput increases. Finally, it promoted an increase in GDP and formed a positive feedback loop.

(6) Loop 6. Increase of port throughput $\longrightarrow$ waste gas, sulfur dioxide, COD, and wastewater emissions $\longrightarrow$ the cost of environmental protection investment $\longrightarrow \mathrm{GDP}$

With the increase of port throughput, the emissions of waste gas, sulfur dioxide, COD, and wastewater 


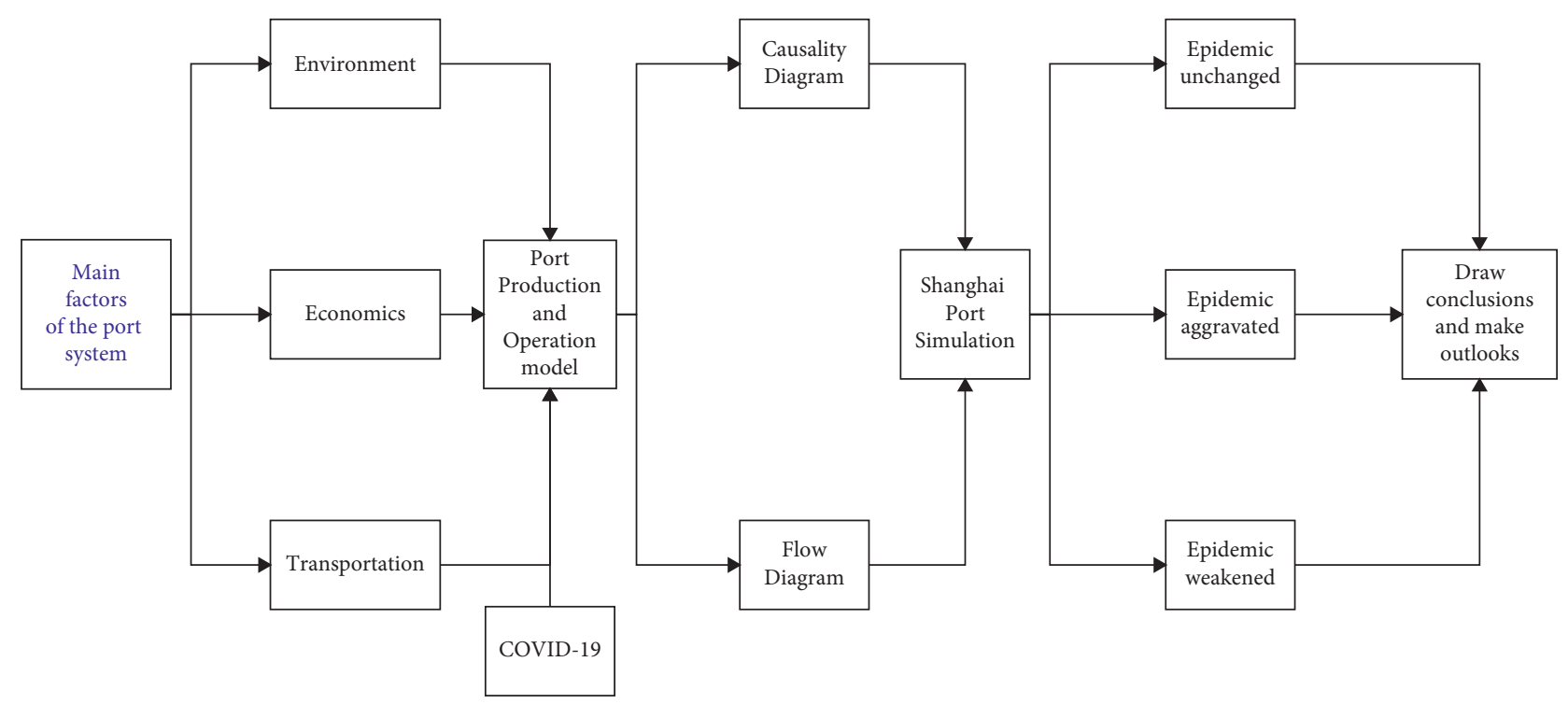

Figure 1: Research route map.

will increase, and then the cost of environmental protection investment will increase. Finally, the GDP is affected.

There are other influencing factors considered in this model, including the impact of passenger transportation on port throughput, the impact of cargo traffic on collection and distribution capacity, and the impact of collection and distribution capacity on port throughput. Besides, the impacts of the COVID-19 epidemic on GDP, consumer goods retail, industrial output, transportation, storage, and postal industry, import and export trade, cargo transportation volume, and passenger volume are also included. These effects also affect the port throughput through the feedback loop.

When the above feedback loop and other main factors are determined, then use VENSIM modeling software to draw the causal feedback loop, as shown in Figure 2. Different colors represent different causal cycles.

\subsection{Establishment of Flow Diagram of Port Production and} Operation. The flow diagram is the basic form of System Dynamics structure model. Drawing a flow diagram based on the causal feedback loop is an important step in system dynamics. To draw a flow diagram based on a causal feedback diagram, some parameters need to be extended, such as level variables, rate variables, constants, and auxiliary variables. There are the names and quantities of these variables as shown in Table 1.

Flow diagram of port production and operation is as shown in Figure 3.

\section{Model Simulation: Taking Shanghai Port as an Example}

4.1. The Main System Dynamics Equations in the Model. The main equations in the model are shown in Table 2. Among them, the initial time of the simulation is 2011, the end time is 2022, and the step length is 1 year.
4.2. Parameter Sources and Calculation Steps. This study selects data from 2011 to 2020, which come from the Shanghai Statistical Yearbook, Ministry of Transport of the People's Republic of China, Shanghai Bureau of Statistics, Shanghai Customs, China Port Yearbook, and so on. The specific parameters and calculation steps are as follows:

(1) Table Function. Apply SPSS software to simulate to get the forecast data by building the Autoregressive Integrated Moving Average (ARIMA) model based on the data from 2011 to 2019. Then apply the VENSIM software to establish a table function for social consumer goods retail growth rate, industrial output growth rate, import and export growth rate, storage and postal industry growth rate, and so on.

(2) Regression Analysis. Apply SPSS to make regress analysis of related variables, such as coefficient of transportation, storage, and postal industry on port throughput conversion into domestic trade, coefficient of industrial output conversion into domestic trade, coefficient of social consumer goods retail conversion into domestic trade, and coefficient of import and export conversion into foreign trade.

(3) Mean Value. Select the data from the 2011-2019 Shanghai Statistical Yearbook to calculate the mean value by Excel, such as social consumer goods retail to GDP ratio, industrial output to GDP ratio, and import and export total trade to GDP ratio.

(4) Calculate the real GDP of a year:

$$
\text { Real GDP } x=\frac{\text { GDP Index }_{x} \times \mathrm{GDP}_{1978}}{\text { GDP Index }_{1978}},
$$

where Real GDP $x$ represents the real GDP in year $X$, GDP Index $x$ represents the GDP Index in year $X$, and GDP Index 1978 represents the GDP Index in 1978 (the GDP Index in 1978 was equal to 100 by default). The GDP Index 


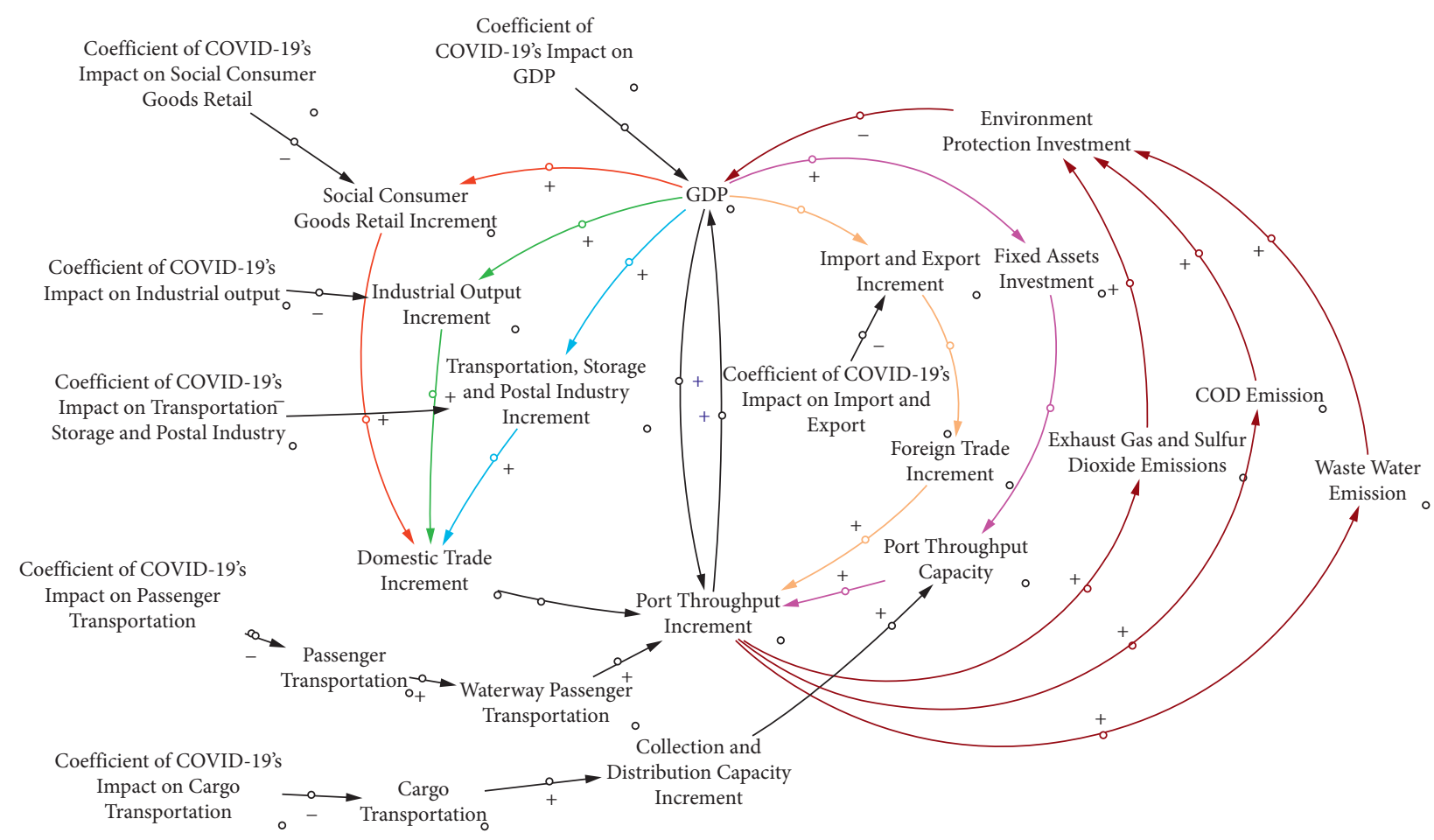

Figure 2: Causal feedback loop of port production and operation.

TABLE 1: Variables in the flow diagram.

\begin{tabular}{lc} 
Type & Name \\
\hline Level (L) & GDP, port throughput, domestic trade cargo throughput, foreign trade cargo throughput, passenger \\
transportation, port throughput capacity, and cargo transportation
\end{tabular}

GDP increment, GDP decrement, port throughput increment, domestic trade cargo throughput increment,

Rate (R) foreign trade cargo throughput increment, passenger transportation increment, cargo transportation capacity increment, and cargo transportation increment

Growth rate of social consumer goods retail, coefficient of COVID-19's impact on social consumer goods retail and industrial output productivity, coefficient of COVID-19's impact on industrial output, coefficient of COVID19's impact on industry in transportation, storage, and postal, coefficient of COVID-19's impact on passenger transportation, real GDP, nominal real ratio, real GDP growth rate, coefficient of epidemic impact on GDP, coefficient of epidemic impact on foreign trade cargo throughput, coefficient of epidemic impact on domestic trade cargo throughput, other import and export trade growth rates, growth rates of medical instruments' import and export trade, growth rates of medicine import and export trade, coefficient of COVID-19's impact on cargo transportation, cargo transportation growth rate, total of social consumer goods retail, social consumer goods

retail increment, industrial output, industrial output increment, industry increment and total output in transportation, storage, and postal, waterway passenger transportation, other import and export trades, other

Auxiliary (A) import and export to GDP ratios, coefficient of COVID-19's impact on other import and export trades, other import and export trade increments, medical instrument import and export trade, medical instrument import and export trade to GDP ratio, coefficient of COVID-19's impact on medical instrument import and export, coefficient of COVID-19's impact on medicine import and export, medicine import and export total trade, medicine import and export to GDP ratio, fixed assets investment, influence coefficient of port throughput capacity on port throughput, total import and export increment, road collection and distribution capacity, railway collection and distribution capacity, air collection and distribution capacity, waterway collection and distribution capacity, port collection and distribution capacity increment, influence coefficient of exhaust gas and sulfur dioxide on port throughput, exhaust gas and sulfur dioxide emissions, wastewater emissions, influence coefficient of COD on port throughput, COD emissions, total pollution emissions, and environmental protection 
TABLE 1: Continued.

\begin{tabular}{ll}
\hline Type & Name \\
\hline & Social consumer goods retail to GDP ratio, industrial output to GDP ratio, transportation, storage, and postal \\
industry to GDP ratio, transportation, storage, and postal industry growth rate, coefficient of transportation, \\
storage, and postal industry conversion into domestic trade, coefficient of industrial output conversion into \\
domestic trade, coefficient of social consumer goods retail conversion into domestic trade, growth coefficient of \\
passenger transportation, growth coefficient of domestic trade, growth coefficient of waterway passenger, growth \\
constants \\
coefficient of waterway passenger transportation, growth coefficient of foreign trade, impact coefficient of port \\
throughput on GDP, fixed asset investment to GDP ratio, fixed assets conversion rate, coefficient of collection and \\
distribution capacity conversion into port throughput capacity, coefficient of import and export conversion into \\
foreign trade, road rate, railway rate, waterway rate, air rate, road collection, and distribution capacity growth \\
rate, railway collection and distribution capacity growth rate, waterway collection and distribution capacity \\
growth rate, air collection and distribution capacity growth rate, coefficient of wastewater discharged by port \\
throughput, pollution emission treatment coefficient, and pollution emission constant
\end{tabular}

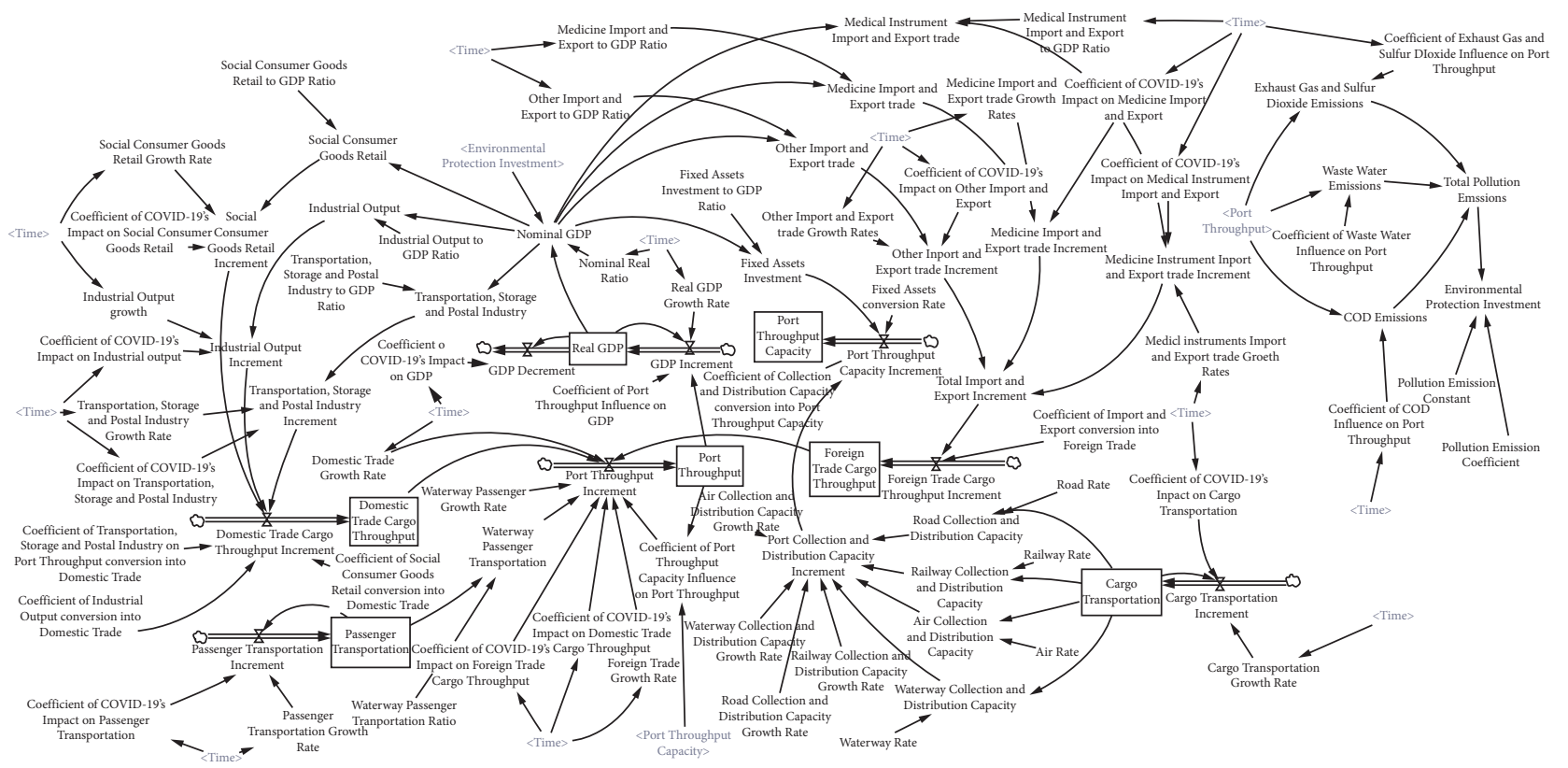

FIGURE 3: Flow diagram of port production and operation.

from 1978 to 2018 can be found in the Shanghai Statistical Yearbook.

Determination of the initial value of the model is as shown in Table 3.

Comparison of simulation results and actual results of GDP is shown in Table 4.

Comparison of simulation results and actual results of port throughput is shown in Table 5.

By analyzing the relative error of GDP and port throughput, it is found that the average relative error of GDP is $1.83 \%$, and the average relative error of port throughput is $1.33 \%$, both of which are less than $5 \%$. Therefore, it can be considered that the parameter setting of the model is reasonable and the simulation is accurate. It also shows that the model can better explain the impact of COVID-19 on ports.

4.3. COVID-19 Scenario Setting. COVID-19 had an important impact on GDP, social consumer goods retail, industrial output, transportation, storage, and postal industry, passenger transportation, cargo transportation, import and export trade, and domestic and foreign trade throughput. We evaluate the impact of COVID-19 through influence coefficients.

\subsubsection{Impact on GDP.}

$$
\mathrm{CIC}_{\mathrm{GDP}}=\frac{\mathrm{GDP}_{2020}-\mathrm{AGDP}_{2020}}{\mathrm{AGDP}_{2020}} \times 100 \%,
$$

where $\mathrm{CIC}_{\mathrm{GDP}}$ represents the percentage of COVID-19's impact on GDP and $\mathrm{GDP}_{2020}$ represents the real GDP in 2020, calculated by formula (1). AGDP 2020 represents the estimated GDP in 2020, based on the real GDP from 2011 to 2019 by using the ARIMA method. By calculation, we got $\mathrm{CIC}_{\mathrm{GDP}}=3.9 \%$.

\subsubsection{Impact on Social Consumer Goods Retail.}

$$
\mathrm{CIC}_{\text {SCGR }}=\frac{1+\operatorname{SCGRR}_{2020}}{1+\mathrm{ASCGRR}_{2020}} \times 100 \%,
$$


TABle 2: Equations in the model.

\begin{tabular}{|c|c|}
\hline Type & Equation \\
\hline$L$ & Real GDP = INTEG (GDP increment-GDP decrement, initial) \\
\hline$L$ & Port throughput $=$ INTEG $($ port throughput increment, initial) \\
\hline$L$ & Domestic trade cargo throughput $=$ INTEG (domestic trade cargo throughput increment, initial) \\
\hline$L$ & Foreign trade cargo throughput $=$ INTEG (foreign trade cargo throughput increment, initial) \\
\hline$L$ & Passenger transportation = INTEG (passenger transportation increment, initial) \\
\hline$L$ & Port throughput capacity $=$ INTEG (port throughput capacity increment, initial) \\
\hline$L$ & Cargo transportation $=$ INTEG $($ cargo transportation increment, initial) \\
\hline$R$ & GDP increment $=$ real GDP $*$ real GDP growth rate + port throughput $*$ coefficient of port throughput impact on GDP \\
\hline$R$ & GDP decrement $=$ coefficient of COVID-19's impact on GDP $*$ real GDP \\
\hline$R$ & $\begin{array}{c}\text { Port throughput increment }=(\text { domestic trade cargo throughput } * \text { domestic trade growth rate } * \text { coefficient of COVID-19's impact } \\
\text { on domestic trade cargo throughput }+ \text { foreign trade cargo throughput } * \text { foreign trade growth rate } * \text { coefficient of COVID-19's } \\
\text { impact on foreign trade cargo throughput }) * \text { impact coefficient of port throughput capacity on port throughput + waterway } \\
\text { passenger transportation } * \text { waterway passenger growth rate }\end{array}$ \\
\hline$R$ & $\begin{array}{l}\text { Domestic trade cargo throughput increment }=\text { transportation, storage, and postal industry increment } * \text { coefficient of } \\
\text { transportation, storage, and postal industry on port throughput conversion into domestic trade }+ \text { industrial output increment } * \\
\text { coefficient of industrial output conversion into domestic trade }+ \text { social consumer goods retail increment } * \text { coefficient of social } \\
\text { consumer goods retail conversion into domestic trade }\end{array}$ \\
\hline$R$ & $\begin{array}{l}\text { Foreign trade cargo throughput increment }=\text { total import and export increment } * \text { coefficient of import and export conversion into } \\
\text { foreign trade }\end{array}$ \\
\hline$R$ & $\begin{array}{c}\text { Passenger transportation increment }=\text { passenger transportation } * \text { passenger transportation growth rate - coefficient of COVID-19's } \\
\text { impact on passenger transportation } * \text { passenger transportation }\end{array}$ \\
\hline$R$ & $\begin{array}{l}\text { Port throughput capacity }=\text { fixed assets investment } * \text { fixed assets conversion rate }+ \text { port collection and distribution capacity } \\
\text { increment } * \text { coefficient of collection and distribution capacity conversion into port throughput capacity }\end{array}$ \\
\hline$R$ & $\begin{array}{c}\text { Cargo transportation increment }=\text { cargo transportation } * \text { cargo transportation growth rate-coefficient of COVID-19's impact on } \\
\text { cargo transportation } * \text { cargo transportation }\end{array}$ \\
\hline$A$ & Conditional function form, for instance: coefficient of COVID-19's impact on GDP = IF THEN ELSE(Time <2019, 0, 0.039) \\
\hline$A$ & $\begin{array}{l}\text { Multiply form, for instance: increment of port collection and distribution capacity }=\text { road collection and distribution capacity } * \\
\text { growth rate of road collection and distribution capacity + waterway collection and distribution capacity } * \text { growth rate of waterway } \\
\text { collection and distribution capacity + air collection and distribution capacity } * \text { growth rate of air collection and distribution } \\
\text { capacity + railway collection and distribution capacity } * \text { growth rate of railway collection and distribution capacity }\end{array}$ \\
\hline A & Product form, for instance: industrial output $=$ industrial output to GDP ratio $*$ nominal GDP \\
\hline$A$ & $\begin{array}{l}\text { Table function form, for instance: real GDP growth rate }=([(2011,0)-(2022,0.09)],(2011,0.075),(2012,0.079),(2013,0.071) \text {, } \\
(2014,0.07),(2015,0.068),(2016,0.069),(2017,0.066),(2018,0.06),(2019,0.056),(2020,0.056),(2021,0.055),(2022,0.054))\end{array}$ \\
\hline
\end{tabular}

TABle 3: Determination of the initial value of the model.

\begin{tabular}{lccc}
\hline Parameter & Initial value & Units & Data source \\
\hline Real GDP & 6763 & Hundred million RMB & Calculated by nominal GDP and GDP Index \\
Port throughput & 72758 & Ten thousand tons & 2019 Shanghai Statistical Yearbook \\
Domestic trade cargo throughput & 38980 & Ten thousand tons & 2019 Shanghai Statistical Yearbook \\
Foreign trade cargo throughput & 33778 & Ten thousand tons & 2019 Shanghai Statistical Yearbook \\
Passenger transportation & 13519 & Ten thousand people & 2019 Shanghai Statistical Yearbook \\
Port throughput capacity & 4.6 & Hundred million tons & 2011 China Port Yearbook \\
Cargo transportation & 93318 & Ten thousand tons & 2019 Shanghai Statistical Yearbook \\
\hline
\end{tabular}

TABLE 4: Comparison of simulation results and actual results of GDP.

\begin{tabular}{lccc}
\hline Year & Nominal GDP & Simulation GDP & Relative error (\%) \\
\hline 2011 & 19539 & 18941 & 3.1 \\
2012 & 20558 & 20001 & 2.7 \\
2013 & 22264 & 21801 & 2.1 \\
2014 & 24068 & 23661 & 1.7 \\
2015 & 25659 & 25139 & 2.0 \\
2016 & 27466 & 26879 & 2.1 \\
2017 & 30134 & 29595 & 1.8 \\
2018 & 32680 & 32196 & 1.5 \\
2019 & 38155 & 37893 & 0.7 \\
2020 & 38701 & 38479 & 0.6 \\
\hline
\end{tabular}

TABle 5: Comparison of simulation results and actual results of port throughput.

\begin{tabular}{cccc}
\hline Year & Actual results & Simulation results & Relative error $(\%)$ \\
\hline 2011 & 72758 & 72758 & 0.0 \\
2012 & 73559 & 74178 & 0.8 \\
2013 & 77575 & 80489 & 3.8 \\
2014 & 75529 & 77233 & 2.3 \\
2015 & 71740 & 71454 & 0.4 \\
2016 & 70177 & 69190 & 1.5 \\
2017 & 75051 & 75626 & 0.8 \\
2018 & 73048 & 72435 & 0.8 \\
2019 & 72031 & 71595 & 0.6 \\
2020 & 71670 & 69995 & 2.3 \\
\hline
\end{tabular}


where CIC $_{\text {SCGR }}$ represents the coefficient of COVID-19's impact on social consumer goods retail and SCGRR 2020 represents the social consumer goods retail growth rate in 2020, which could be obtained from the official website of the Shanghai Bureau of Statistics. ASCGRR 2020 represents the estimated growth rate of social consumer goods retail in 2020 , which was calculated by the ARIMA method based on the growth rate of the social consumer goods retail from 2011 to 2019. By calculation, we got $\mathrm{CIC}_{\mathrm{SCGR}}=94 \%$.

\subsubsection{Impact on Industrial Output.}

$$
\mathrm{CIC}_{\mathrm{IO}}=\frac{1+\mathrm{IOR}_{2020}}{1+\mathrm{AIOR}_{2020}} \times 100 \%,
$$

where $\mathrm{CIC}_{\mathrm{IO}}$ represents the coefficient of COVID-19's impact on industrial output and $\mathrm{IOR}_{2020}$ represents the industrial output growth rate in 2020 which could be obtained from the official website of the Shanghai Bureau of Statistics. AIOR 2020 represents the estimated growth rate of industrial output in 2020, which was calculated by the ARIMA method based on the growth rate of industrial output from 2011 to 2019. By calculation, we got $\mathrm{CIC}_{\mathrm{IO}}=101 \%$.

\subsubsection{Impact on Transportation, Storage, and Postal Industry.}

$$
\mathrm{CIC}_{\mathrm{TSP}}=\frac{1+\mathrm{TSPR}_{2020}}{1+\mathrm{ATSPR}_{2020}} \times 100 \%,
$$

where $\mathrm{CIC}_{\mathrm{TSP}}$ represents the coefficient of COVID-19's impact on transportation, storage, and postal industry and $\mathrm{TSPR}_{2020}$ represents the growth rate of transportation, storage, and postal industry, which could be obtained from the official website of the Shanghai Bureau of Statistics. $\mathrm{ATSPR}_{2020}$ represents the estimated growth rate of industrial output in 2020, which was analyzed by the ARIMA method based on the growth rate of the industrial output from 2011 to 2019. By calculation, we got $\mathrm{CIC}_{\mathrm{TSP}}=85 \%$.

\subsubsection{Impact on Passenger Transportation.}

$$
\mathrm{CIC}_{P}=\frac{P_{2020}-A P_{2020}}{A P_{2020}} \times 100 \%,
$$

where $\mathrm{CIC}_{P}$ represents the coefficient of COVID-19's impact on passenger transportation and $P_{2020}$ represents the passenger transportation in 2020, which could be obtained from the official website of the Shanghai Bureau of Statistics. $A P_{2020}$ represents the estimated growth rate of passenger transportation in 2020, which was analyzed by the ARIMA method based on the growth rate of the passenger transportation from 2011 to 2019. By calculation, we got $\mathrm{CIC}_{P}=52 \%$.

\subsubsection{Impact on Cargo Transportation.}

$$
\mathrm{CIC}_{C}=\frac{C_{2020}-A C_{2020}}{A C_{2020}} \times 100 \%,
$$

where $\mathrm{CIC}_{C}$ represents the coefficient of COVID-19's impact on cargo transportation and $C_{2020}$ represents the cargo transportation in 2020, which could be obtained from the official website of the Shanghai Bureau of Statistics. $A C_{2020}$ represents the estimated growth rate of cargo transportation in 2020, which was analyzed by the ARIMA method based on the growth rate of cargo transportation from 2011 to 2019. By calculation, we got $\mathrm{CIC}_{C}=11 \%$.

\subsubsection{Impact on Import and Export Trade.}

$$
\mathrm{CIC}_{\text {IEP }}=\frac{1+\mathrm{IEPR}_{2020}}{1+\mathrm{AIEPR}_{2020}} \times 100 \% \text {, }
$$

where $\mathrm{CIC}_{\text {IEP }}$ represents the coefficient of COVID-19's impact on medicine import and export and IEPR 2020 represents the growth rate of medicine import and export trade in 2020 obtained from the official website of Shanghai Customs. AIEPR 2020 represents the estimated growth rate of the medicine import and export trade, which was analyzed by the ARIMA method based on the growth rate of medicine import and export trade from 2013 to 2019. By calculation, we got $\mathrm{CIC}_{\mathrm{IEP}}=86 \%$

$$
\mathrm{CIC}_{\text {IEME }}=\frac{1+\text { IEMER }_{2020}}{1+\text { AIEMER }_{2020}} \times 100 \%,
$$

where $\mathrm{CIC}_{\text {IEME }}$ represents the coefficient of COVID-19's impact on medical instrument import and export and IEMER $_{2020}$ represents the growth rate of medical instrument import and export trade in 2020 obtained from the official website of Shanghai Customs. AIEMER 2020 represents the estimated growth rate of medical instrument import and export trade in 2020 which is analyzed by the ARIMA method based on the growth rate of medical instrument import and export trade from 2013 to 2019. By calculation, we got $\mathrm{CIC}_{\mathrm{IEME}}=90 \%$.

$$
\mathrm{CIC}_{\mathrm{OIE}}=\frac{1+\mathrm{OIER}_{2020}}{1+\mathrm{AOIER}_{2020}} \times 100 \%,
$$

where CIC $_{\text {OIE }}$ represents the coefficient of COVID-19's impact on other import and export trades and OIER 2020 represents the growth rate of other import and export trades in 2020 obtained from the official website of Shanghai Customs. AOIER 2020 represents the estimated growth rate of other import and export trades in 2020 which was analyzed by the ARIMA method based on the growth rate of other import and export trades from 2013 to 2019. By calculation, we got $\mathrm{CIC}_{\mathrm{OIE}}=99 \%$.

$$
\begin{aligned}
& \text { 4.3.8. Impact on Trade Throughput. } \\
& \qquad \mathrm{CIC}_{\mathrm{DT}}=\frac{1+D T R_{2020}}{1+\mathrm{ADTR}_{2020}} \times 100 \% \text {, }
\end{aligned}
$$

where $\mathrm{CIC}_{\mathrm{DT}}$ represents the coefficient of COVID-19's impact on domestic trade throughput and $\mathrm{DTR}_{2020}$ represents the growth rate of domestic trade throughput in 2020 obtained from the official website of the Shanghai Bureau of Statistics. ADTR 2020 represents the estimated growth rate of 
domestic trade throughput in 2020 which was analyzed by the ARIMA method based on the growth rate of domestic trade throughput from 2011 to 2019. By calculation, we got $\mathrm{CIC}_{\mathrm{DT}}=102 \%$.

$$
\mathrm{CIC}_{\mathrm{FT}}=\frac{1+\mathrm{FTR}_{2020}}{1+\mathrm{AFTR}_{2020}} \times 100 \%,
$$

where $\mathrm{CIC}_{\mathrm{FT}}$ represents the coefficient of COVID-19's impact on foreign trade throughput and $\mathrm{FTR}_{2020}$ represents the growth rate of foreign trade throughput in 2020 obtained from the official website of the Shanghai Bureau of Statistics. $\mathrm{AFTR}_{2020}$ represents the estimated growth rate of foreign trade throughput in 2020 which was analyzed by the ARIMA method based on the growth rate of the foreign trade throughput from 2011 to 2019. By calculation, we got $\mathrm{CIC}_{\mathrm{DT}}=101 \%$.

4.4. COVID-19 Epidemic Simulation. To study the impact of COVID-19 on the port operation system, we make assumptions about the following data: coefficients of COVID19's impact on GDP, social consumer goods retail, industrial output, industry in transportation, storage and postal, passenger transportation, foreign trade cargo throughput, domestic trade cargo throughput, cargo transportation, and import and export trade.

Assuming that COVID-19 did not occur, the value of the main variables is shown in Figure 4.

Three scenarios are distinguished in the following to evaluate the 5 impact of COVID-19 on ports :6 7 .

(1) The first scenario: COVID-19 epidemic continues like 2020 and the impact of the epidemic on all factors remains unchanged. Assuming that $\mathrm{CIC}_{\mathrm{GDP}}$, $\mathrm{CIC}_{\mathrm{SCGR}}, \mathrm{CIC}_{\mathrm{TSP}}, \mathrm{CIC}_{P}, \mathrm{CIC}_{C}, \mathrm{CIC}_{\mathrm{IEP}}, \mathrm{CIC}_{\mathrm{IEME}}$, $\mathrm{CIC}_{\mathrm{OIE}}, \mathrm{CIC}_{\mathrm{DT}}$, and $\mathrm{CIC}_{\mathrm{FT}}$ are unchanged in 2021 and 2022, the predicted values of the main variables and the impact of COVID-19 on the main variables are shown in Figure 5 and Table 6, respectively. The impact of COVID-19 on the main variables was calculated based on the data as shown in Figure 5 .

From 2020 to 2022, the estimated GDP, respectively, reduced by $-3.8 \%,-7.4 \%$, and $-10.9 \%$. The epidemic impact on port throughput is $-0.03 \%,-0.08 \%$, and $-0.1 \%$. The impact on passenger transportation is very serious, reaching $-49.1 \%,-49.2 \%$, and $-49.1 \%$. The impact on cargo transportation is $-10.6 \%$, $-20.1 \%$, and $-28.6 \%$, respectively.

(2) The second scenario: when COVID-19 epidemic is aggravated. When the impact of COVID-19 on various factors increases by $10 \%$ based on the first situation, $\mathrm{CIC}_{\mathrm{GDP}}$ is $43 \%$ and $47 \%, \mathrm{CIC}_{\mathrm{SCGR}}$ is $85 \%$ and $78 \%, \mathrm{CIC}_{\mathrm{IO}}$ is $92 \%$ and $84 \%, \mathrm{CIC}_{\mathrm{TSP}}$ is $77 \%$ and $70 \%, \mathrm{CIC}_{P}$ is $57 \%$ and $63 \%, \mathrm{CIC}_{C}$ is $12 \%$ and $13 \%$, $\mathrm{CIC}_{\mathrm{IEP}}$ is $77 \%$ and $70 \%, \mathrm{CIC}_{\mathrm{IEME}}$ is $81 \%$ and $73 \%$, $\mathrm{CIC}_{\mathrm{OIE}}$ is $89 \%$ and $80 \%, \mathrm{CIC}_{\mathrm{DT}}$ is $93 \%$ and $85 \%$, and $\mathrm{CIC}_{\mathrm{FT}}$ is $92 \%$ and $84 \%$.

The predicted values of the main variables and the impact of COVID-19 on the main variables are

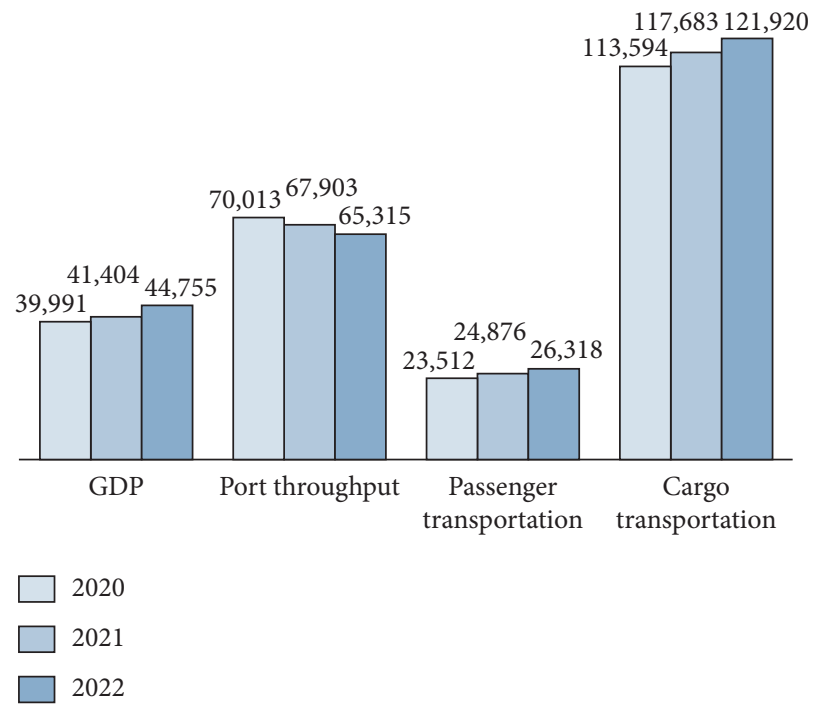

FIGURE 4: Simulation prediction when COVID-19 does not occur.

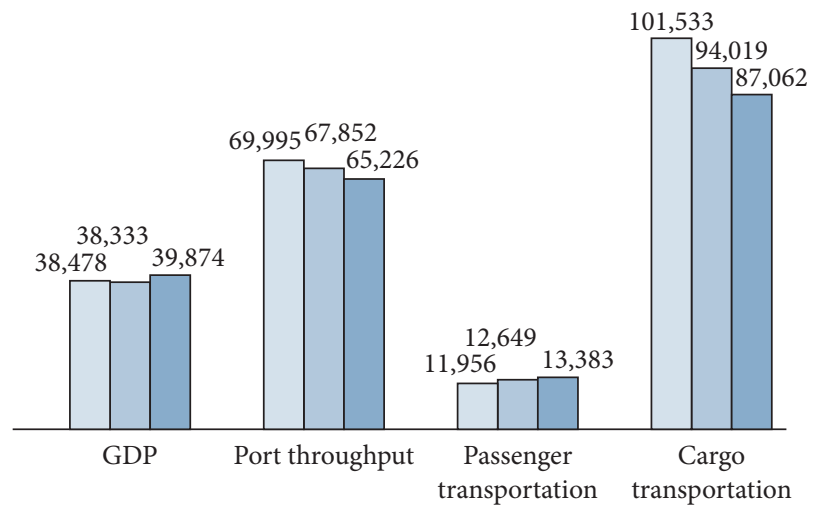

2020

2021

2022

FIGURE 5: Simulation prediction when COVID-19 epidemic is unchanged.

shown in Figure 6 and Table 7, respectively. The impact of COVID-19 on the main variables was calculated based on the data shown in Figure 6.

In Table 7 when the epidemic is aggravated, the impact of COVID-19 on GDP is $-3.8 \%,-7.8 \%$, and $-12.0 \%$ from 2020 to 2022 . The impact of COVID-19 on port throughput is $-0.03 \%, 0.2 \%$, and $0.8 \%$. The impact of COVID-19 on passenger transportation is $-49.1 \%,-76.5 \%$, and $-90.5 \%$. The impact of COVID-19 on Cargo transportation is $-10.6 \%$, $-21.0 \%$, and $-30.9 \%$.

(3) The third scenario: when the COVID-19 epidemic is weakened. When the impact of COVID-19 on various factors decreases by $10 \%$ based on the first situation, $\mathrm{CIC}_{\mathrm{GDP}}$ is $35 \%$ and $32 \%, \mathrm{CIC}_{\mathrm{SCGR}}$ is $103 \%$ and $114 \%, \mathrm{CIC}_{\mathrm{IO}}$ is $111 \%$ and $122 \%, \mathrm{CIC}_{\mathrm{TSP}}$ is $94 \%$ and $103 \%, \mathrm{CIC}_{P}$ is $47 \%$ and $42 \%, \mathrm{CIC}_{C}$ is $10 \%$ and 


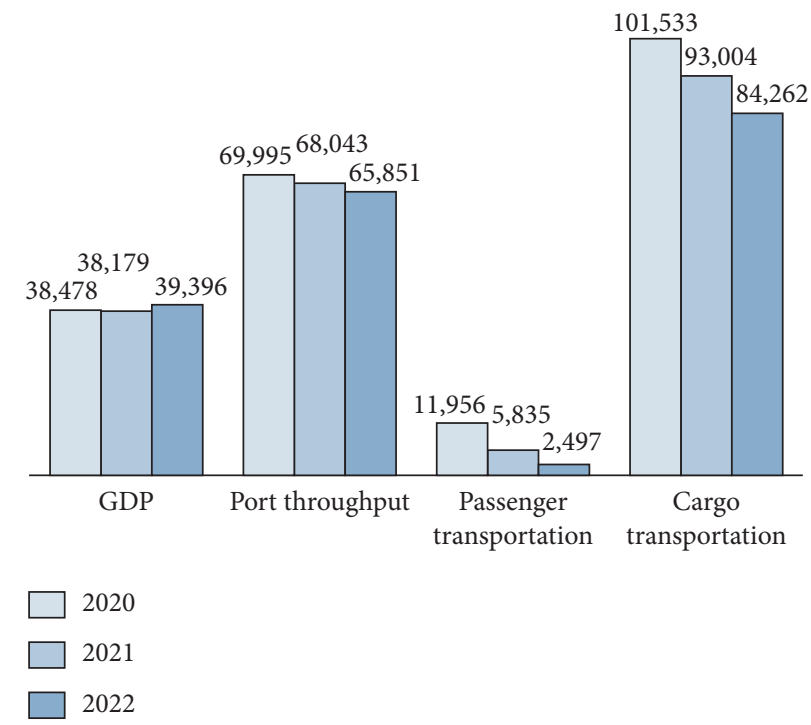

FIGURE 6: Simulation prediction when COVID-19 epidemic is aggravated.

TABLE 6: The impact of COVID-19 on main variables.

\begin{tabular}{lcccc}
\hline Year & GDP (\%) & Port throughput (\%) & Passenger transportation (\%) & Cargo transportation (\%) \\
\hline 2020 & -3.8 & -0.03 & -49.1 & -10.6 \\
2021 & -7.4 & -0.08 & -49.2 & -20.1 \\
2022 & -10.9 & -0.1 & -49.1 & -28.6 \\
\hline
\end{tabular}

TABLE 7: The impact of COVID-19 epidemic on the main variables when epidemic is aggravated.

\begin{tabular}{lcccc}
\hline Year & GDP (\%) & Port throughput (\%) & Passenger transportation (\%) & Cargo transportation (\%) \\
\hline 2020 & -3.8 & -0.03 & -49.1 & -10.6 \\
2021 & -7.8 & 0.2 & -76.5 & -21.0 \\
2022 & -12.0 & 0.8 & -90.5 & -30.9 \\
\hline
\end{tabular}

$9 \%, \mathrm{CIC}_{\mathrm{IEP}}$ is $95 \%$ and $104 \%, \mathrm{CIC}_{\mathrm{IEME}}$ is $99 \%$ and $109 \%, \mathrm{CIC}_{\mathrm{OIE}}$ is $109 \%$ and $120 \%, \mathrm{CIC}_{\mathrm{DT}}$ is $112 \%$ and $123 \%$, and $\mathrm{CIC}_{\mathrm{FT}}$ is $111 \%$ and $122 \%$. The epidemic was improved which cause retaliatory growth in GDP, retail of consumer goods, industrial output, transportation, storage, and post, passenger travel, cargo transportation, and import and export trade in a short period.

The predicted values of the main variables and the impact of COVID-19 on the main variables are shown in Figure 7 and Table 8, respectively. The impact of COVID-19 on the main variables was calculated based on the data shown in Figure 7.

In Table 8 when the epidemic is weakened, the impact of COVID-19 on GDP is $-3.8 \%,-1.8 \%$, and $0.04 \%$ from 2020 to 2022 . The impact of COVID-19 on port throughput is $0.03 \%,-0.4 \%$, and $-1.3 \%$. The impact of COVID-19 on passenger transportation is $-49.1 \%,-32.7 \%$, and $-7.8 \%$. The impact of COVID-19 on cargo transportation is $-10.6 \%$, $-6.8 \%$, and $-2.0 \%$.

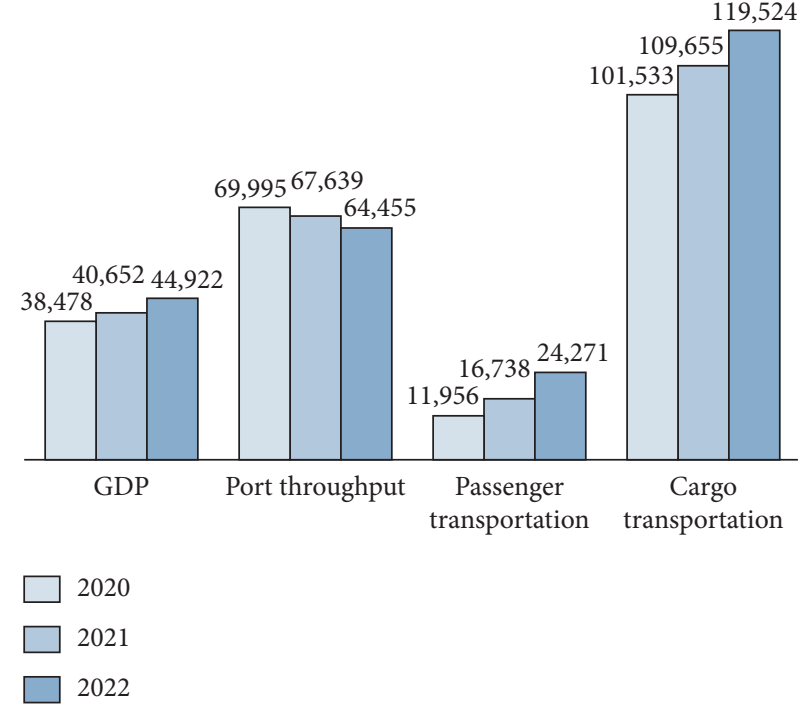

Figure 7: Simulation prediction when COVID-19 is weakened. 
TABLE 8: The impact on the main variables when COVID-19 epidemic is weakened.

\begin{tabular}{lcccc}
\hline Year & GDP (\%) & Port throughput (\%) & Passenger transportation (\%) & Cargo transportation (\%) \\
\hline 2020 & -3.8 & -0.03 & -49.1 & -10.6 \\
2021 & -1.8 & -0.4 & -32.7 & -6.8 \\
2022 & 0.04 & -1.3 & -7.8 & -2.0 \\
\hline
\end{tabular}

\section{Conclusion and Outlook}

Taking into account several factors including GDP, port throughput, domestic and foreign trade, passengers and cargo transportation, port throughput capacity, and environmental pollution, we established the system dynamics model to study the impact of COVID-19 on port production and operation and found that the impact of COVID-19 on port production and operation had different performance under three different epidemic situations:

(1) When the COVID-19 epidemic continues like 2020. From 2020 to 2022, the estimated GDP, respectively, reduced by $-3.8 \%,-7.4 \%$, and $-10.9 \%$. The epidemic impact on port throughput is $-0.03 \%,-0.08 \%$, and $-0.1 \%$. The impact on passenger transportation is $-49.1 \%,-49.2 \%$, and $-49.1 \%$, and the impact on cargo transportation is $-10.6 \%,-20.1 \%$, and $-28.6 \%$.

(2) When the COVID-19 epidemic is aggravated. From 2020 to 2022, the impact of COVID-19 on GDP is $-3.8 \%,-7.8 \%$, and $-12.0 \%$. The impact of COVID19 on port throughput is $-0.03 \%, 0.2 \%$, and $0.8 \%$. The impact of COVID-19 on passenger transportation is $-49.1 \%,-76.5 \%$, and $-90.5 \%$, and the impact of COVID-19 on cargo transportation is $-10.6 \%,-21.0 \%$, and $-30.9 \%$.

(3) When the COVID-19 epidemic is weakened. From 2020 to 2022, the impact of COVID-19 on GDP is $-3.8 \%,-1.8 \%$, and $0.04 \%$. The impact of COVID-19 on port throughput is $0.03 \%,-0.4 \%$, and $-1.3 \%$. The impact of COVID-19 on passenger transportation is $-49.1 \%,-32.7 \%$, and $-7.8 \%$, and the impact of COVID-19 on cargo transportation is $-10.6 \%$, $-6.8 \%$, and $-2.0 \%$.

Based on the above research, the following countermeasures are proposed:

(1) The epidemic mainly has a greater impact on passenger transportation, although the impact on ports that dominate cargo transportation is relatively small. The ports assembled the function of transportation in highway, railway, and waterway and were the key nodes in the international logistics network. We must pay more attention to the impact of the epidemic on the port. It is necessary to strengthen the port's collection and distribution capabilities, improve port production efficiency, and further strengthen port modernization.

(2) As the epidemic situation abroad remains severe, port enterprises should be prepared for the possible recurrence of the epidemic (Wu et al. [38]) to ensure smooth port transportation and normal production operations by strengthening the information linkage between domestic and foreign ports, improving the port's epidemic prevention and control capabilities.

(3) The cargo backlog in the docks, warehousing, and distribution centers left a large number of containers stranded, resulting in high detention fees. Therefore, we should help the port production and operation to get through difficult times by reducing or exempting some cargo port fees and decreasing berthing fees and cargo storage costs.

The research method proposed in the paper can provide a reference for the impact assessment of similar emergencies, and the empirical results can provide a reference for handling the epidemic shock for the port and shipping departments.

Of course, there are some shortcomings in this study: (1) Lack of comprehensive consideration in influencing factors: due to lack of data, there are several influencing factors not considered in this paper such as work stoppage, the decline in the number of healthy workers caused by the epidemic, and the restrictions on foreign flights to China in the early stage of the COVID-19 outbreak. (2) No lag effect of variables: the impact of these variables including rate variables, auxiliary variables, weather variables ( $\mathrm{Wu}$ et al. [39]), and constants occurred immediately without considering the effect delay of some variables. (3) Parameter calculation problem: the parameters were mainly determined by using the table function method, regression analysis method, and mean value method. In future, we should consider other different methods to calculate parameters more reasonably. These shortcomings need further research.

\section{Data Availability}

The data will be provided when required.

\section{Conflicts of Interest}

The authors declare that there are no conflicts of interest.

\section{Acknowledgments}

This research was supported by the Natural Social Science Foundation of China (17BGL142, 18ZDA052, 16ZDA047, 91546117, and 71904117).

\section{References}

[1] C. X. XU, Y. X. Yan, and P. Zhang, "Prediction model of port throughput based on system dynamics," Water Transport Engineering, vol. 5, pp. 26-28+40, 2006. 
[2] W. X. Luan, H. Chen, and Y. W. Wang, "Simulating mechanism of interaction between ports and cities based on system dynamics: a case of Dalian, China," Chinese Geographical Science, vol. 20, no. 5, pp. 398-405, 2010.

[3] Y. L. Jiang, Z. H. Tian, B. Yu, and J. Ly, "System dynamics based port's landside consolidation system in port cities," Journal of Dalian Maritime University, vol. 39, no. 2, pp. 65-68, 2013.

[4] B. Yu, C. Zhang, L. Kong et al., "System dynamics modeling for the land transportation system in a port city," SimulationTransactions of the Society for Modeling and Simulation International, vol. 90, no. 6, pp. 706-716, 2014.

[5] C. X. Wang and J. X. Cui, "Dynamic analysis model of logistics system of port group in the Yangtze river delta," Journal of Transportation Engineering, vol. 5, pp. 77-83, 2007.

[6] Y. Xi, "Study of combinatorial port based on system dynamics," Journal of System Simulation, vol. 5, pp. 1289-1294, 2008.

[7] H. H. Yu and N. Liu, "Efficiency model of the port group on Yangtze river delta based on system dynamics," Navigation of China, vol. 35, no. 1, pp. 98-104, 2012.

[8] J. Pan, S. Yang, and F. Y. Sheng, "Construction and simulation of port city coupled system model based on systems dynamics: taking Lianyungang as an Example," System EngineeringTheory and Practice, vol. 32, no. 11, pp. 2439-2446, 2012.

[9] L. N. Liu, Z. J. Guo, and X. Q. Song, "Port economy analysis based on system dynamics," Port \&Waterway Engineering, vol. 5, pp. 18-21, 2006.

[10] M. M. Fu and J. Lv, "A system dynamics based on the relationship between port and regional economy," Journal of Dalian Maritime University, vol. 35, no. 4, pp. 43-46, 2009.

[11] J. Hou, "Sustainable development of port economies based on system dynamics," System Engineering-Theory and Practice, vol. 30, no. 1, pp. 56-61, 2010.

[12] Z. F. Guo, H. M. Fan, W. G. Cui, and Y. B. Li, "Dynamic simulation of green and low-carbon port city system co-built by port and city," Ecological Economy, vol. 32, no. 6, pp. 98-102, 2016.

[13] L. Hou and H. Geerlings, "Dynamics in sustainable port and hinterland operations: a conceptual framework and simulation of sustainability measures and their effectiveness, based on an application to the Port of Shanghai," Journal of Cleaner Production, vol. 135, pp. 449-456, 2016.

[14] Q. Zhang, J. F. Zhang, W. Y. Wang, X. Q. Song, and Z. J. Guo, "Dynamic evaluation model of port ecological carrying capacity based on system simulation," Journal of Dalian Maritime University, vol. 43, no. 1, pp. 91-100, 2017.

[15] Y. Q. Wen, X. Q. Geng, B. Wu, C. H. Zhou, and C. S. Xiao, "Research on system dynamics modeling for mitigation of regional vessel exhausts emissions," Environmental Science and Technology, vol. 40, no. 7, pp. 193-199, 2017.

[16] X. Q. Geng, Y. Q. Wen, C. H. Zhou, and C. S. Xiao, "Establishment of the sustainable ecosystem for the regional shipping industry based on system dynamics," Sustainability, vol. 9, no. 5, 2017.

[17] W. Y. Qiao, W. H. Guan, X. G. Wang, and X. Wang, "Study on the dynamics of port-city coupling system based on green concept-a case study of Lianyungang city," Journal of Nanjing Normal University (Natural Science Edition), vol. 41, no. 1, pp. 140-148, 2018.

[18] Y. Li, X. H. Zhang, K. Y. Lin, and Q. B. Huang, "The analysis of a simulation of a port-city green cooperative development, based on system dynamics: a case study of Shanghai port, China," Sustainability, vol. 11, no. 21, 2019.
[19] Y. Mamatok, Y. Y. Huang, C. Jin, and X. Q. Cheng, “A system dynamics model for $\mathrm{CO}_{2}$ mitigation strategies at a container seaport," Sustainability, vol. 11, no. 10, 2019.

[20] H. X. Zheng, G. Y. He, and Y. Q. Sui, "Investment decision to promote green growth of container port economy based on SD," Logistics Technology, vol. 38, no. 7, pp. 55-59, 2019.

[21] X. Zhou, H. Zhen, and N. Zhao, "Policy simulation on Shanghai port energy saving and emission reduction based on system dynamics," China Navigation, vol. 43, no. 2, pp. 86-91+97, 2020.

[22] Q. Feng, H. Y. Jiang, Y. Y. Xie, and S. Y. Yan, "Simulation and prediction of ecological carrying capacity of Qinzhou Port based on system dynamics model," Water Transportation Management, vol. 42, no. 5, pp. 4-8, 2020.

[23] S. P. Zuo, "Research on the coupling green development of Xiamen port and city based on system dynamics model," Heilongjiang Transportation Technology, vol. 43, no. 2, pp. 169-170, 2020.

[24] J. C. Sun, H. Y. Wang, and J. Chen, "Decision-making of port enterprise safety investment based on system dynamics," Processes, vol. 8, no. 10, 2020.

[25] X. Y. Li, Y. Q. Zhang, and Y. Cao, "Impact of port trade on regional economic development based on system dynamics," Journal of Coastal Research, vol. 110, no. sp1, pp. 38-42, 2020.

[26] Y. Y. Huang, M. Yuliy, and C. Jin, "Decision-making instruments for container seaport sustainable development: management platform and system dynamics model," Environment Systems and Decisions, vol. 41, pp. 212-226, 2021.

[27] G. Xiu and Z. Zhao, "Sustainable development of port economy based on intelligent system dynamics," IEEE Access, vol. 9, pp. 14070-14077, 2021.

[28] R. Dawn, R. Kusumal, and R. Violeta, "Managing supply chain uncertainty by building flexibility in container port capacity: a logistics triad perspective and the COVID-19 case," Maritime Economics \& Logistics, 2020.

[29] B. Su, C. L. Guan, Q. An, and Q. N. Wang, "Analysis and countermeasures of the influence of COVID-19 on the commodity category of port export in China: taking Shanghai port as an example," Journal of Coastal Research, vol. 111, no. sp1, pp. 298-301, 2020.

[30] E. Akyurek and P. Bolat, "Port state control at European Union under pandemic outbreak," European Transport Research Review, vol. 10, no. 1, 2020.

[31] T. Notteboom, T. Pallis, and J. P. Rodrigue, "Disruptions and resilience in global container shipping and ports: the COVID19 pandemic versus the 2008-2009 financial crisis," Maritime Economics \& Logistics, vol. 23, pp. 179-210, 2021.

[32] A. Hajar, H. Mhamed, and E. M. Mohamed, "The impact of COVID-19 on the port environment: the case of Tanger Med container port, Morocco," E3S Web of Conferences, vol. 234, 2021.

[33] K. Koyuncu, L. Tavacioglu, N. Gokmen, and U. C. Arican, "Forecasting COVID-19 impact on RWI/ISL container throughput index by using SARIMA models," Maritime Policy \& Management, 2021.

[34] V. Duran-Grados, Y. Amado-Sanchez, F. Calderay-Cayetano et al., "Calculating a drop in carbon emissions in the Strait of Gibraltar (Spain) from domestic shipping traffic caused by the COVID-19 crisis," Sustainability, vol. 12, no. 24, 2020.

[35] L. Curovic, S. Jeram, J. Murovec, T. Novakovic, K. Rupnik, and J. Prezelj, "Impact of COVID-19 on environmental noise emitted from the port," The Science of the Total Environment, vol. 756, 2021. 
[36] N. Zabbey, K. Sam, C. A. Newsom, and P. B. Nyiaghan, "The COVID-19 lockdown: an opportunity for conducting an air quality baseline in Port Harcourt, Nigeria," Extractive Industries and Society-An International Journal, vol. 8, no. 1, pp. 244-256, 2021.

[37] L. Chen, J. J. Li, X. B. Pang et al., "Impact of COVID-19 lockdown on air pollutants in a coastal area of the Yangtze river delta, China, measured by a low-cost sensor package," Atmosphere, vol. 12, no. 3, 2021.

[38] X. H. Wu, Y. L. Cao, Y. Xiao, and J. Guo, "Finding of urban rainstorm and waterlogging disasters based on microblogging data and the location-routing problem model of urban emergency logistics," Annals of Operations Research, vol. 290, no. 1, pp. 865-896, 2020.

[39] X. H. Wu, Z. Xu, H. Liu, J. Guo, and L. Zhou, "What are the impacts of tropical cyclones on employment? an analysis based on meta-regression," Weather, Climate, and Society, vol. 11, pp. 259-275, 2019. 